\title{
Infected Cavitations, Bullae and Interstitial Lung Disease in a COVID-19 Patient in Lima, Peru
}

\author{
$\underline{\text { Francisco Arias }}^{1}$, Alfredo Chiappe ${ }^{1,2}$, Jorge Rey de Castro ${ }^{1}$, Jorge Zagaceta ${ }^{1,2}$ \\ ${ }^{1}$ Clínica Angloamericana, Lima, Peru \\ 2 Facultad de Medicina Humana, Universidad de Piura, Lima, Peru
}

Received: $14 / 10 / 2021$

Accepted: $11 / 11 / 2021$

Published: 29/12/2021

How to cite this article: Arias F, Chiappe A, Rey de Castro J, Zagaceta J. Infected cavitations, bullae and interstitial lung disease in a COVID-19 patient in Lima, Peru. EJCRIM 2021;8: doi:10.12890/2021_003004.

Conflicts of Interests: The authors declare there are no competing interests.

This article is licensed under a Commons Attribution Non-Commercial 4.0 License

\section{ABSTRACT}

A 48-year-old Peruvian man was diagnosed with COVID-19 in December 2020. His infection resolved and he was discharged from hospital after 14 days. However, 1 week later he presented with haemoptysis, malaise, pleuritic pain, infected cavitations, bullae, extensive interstitial lung disease and pneumomediastinum. He recovered after antibiotic treatment and was discharged after 8 days. His symptoms may have been due alveolar rupture due to persistent cough during and after diffuse inflammation of the lung parenchyma caused by COVID-19 infection.

\section{LEARNING POINTS}

- $\quad$ SARS-CoV-2 infection may be associated with lung bullae and cavitations as COVID-19 sequelae.

- $\quad$ Patients with respiratory problems after COVID-19 should be monitored closely and undergo pulmonary tests.

- COVID-19 patients may experience complications for several months due to bacterial infections.

\section{KEYWORDS}

COVID-19, cavitations, bullae, interstitial lung disease, pneumomediastinum

\section{INTRODUCTION}

Since early 2020, the world has been dealing a new virus which can cause variable symptoms and multi-organ complications ${ }^{[1]}$. The first case of coronavirus infection in Peru was detected on 6 March 2020. Subsequently, over 201,450 and more than 2 million cases have been reported ${ }^{[2]}$.

SARS-CoV-2 has been associated with unexpected complications, including coagulopathy, central nervous system disorders and, in particular, lung impairment leading to fibrosis ${ }^{[3]}$.

We present the case of a 48-year-old Peruvian man who travelled to Mexico City for a symposium during the pandemic. He got COVID-19, was hospitalized and was discharged with no complications on Christmas Day 2020. He returned to Lima, Peru but 7 days later presented with haemoptysis, malaise, pleuritic pain and CT findings of infected cavitations, bullae, extensive interstitial lung disease and pneumomediastinum. 


\section{CASE DESCRIPTION}

In early December 2020, a 48-year-old Peruvian man travelled to Mexico City for a symposium. While there he got COVID-19, which was confirmed by molecular testing on 11 December. His medical history included psoriasiform dermatitis but no pulmonary problems. He developed mild disease without the need for oxygen supplementation and was treated with levofloxacin for 7 days (500 mg each day) due to suspected bacterial superinfection. On 20 December 2020, he underwent a CT scan of the lungs, which showed 25\% respiratory compromise (Fig. 1). He was discharged on 25 December with no symptoms and returned to Lima, Peru on 27 December. One week later, he attended a clinic with haemoptysis, malaise and pleuritic pain and was admitted to hospital.

Laboratory examination (Table 1) revealed increased C-reactive protein, lymphopenia and high levels of ferritin. Arterial blood gases were normal. Total serology (IgG+IgM) by CLIA was positive. Immunochromatography showed reactive IgG and non-reactive IgM.

A CT scan of the lungs showed two cavitations, one in each inferior lobe, with an inflammatory process in the right inferior lobe. Diffuse fibrotic bands with increased inflammation of the lung parenchyma of both upper lobes, a $28 \times 14 \mathrm{~cm}$ bulla in the third left segment, a calcified nodule in the third right segment, pneumomediastinum and cervical emphysema were also noted (Fig. 2). An earlier CT scan of the abdomen and lungs taken 1 year previously had not shown any lung alterations (Fig. 3).

The patient was also screened for bacterial infections and tuberculosis.

The antibiotics ceftriaxone $2 \mathrm{~g}$ intravenously (IV) once a day and clindamycin $600 \mathrm{mg}$ IV every 8 hours were administered. Codeine was given to treat cough, which improved.

The infectious diseases and thoracic surgery departments were consulted regarding antibiotic therapy. The infectious diseases specialist suggested an additional search for Paragonimus spp. because the patient had previously visited endemic areas of Mexico, and recommended that antibiotics be given for a total of 6 weeks because of the suspicion of infected lung cavitations or bullae, due to their thick walls and airfluid level, resembling lung abscesses. A thoracic surgeon was consulted and indicated surgery would not be beneficial.

The patient recovered during his time in hospital. He did not develop fever, dyspnoea or desaturation. His pleuritic pain resolved within days. He completed his 7-day course of antibiotic therapy and after 8 days was discharged on oral cefixime $400 \mathrm{mg}$ once a day plus oral clindamycin $300 \mathrm{mg}$ three times a day for 5 more weeks with periodic follow-up in the outpatient clinic.

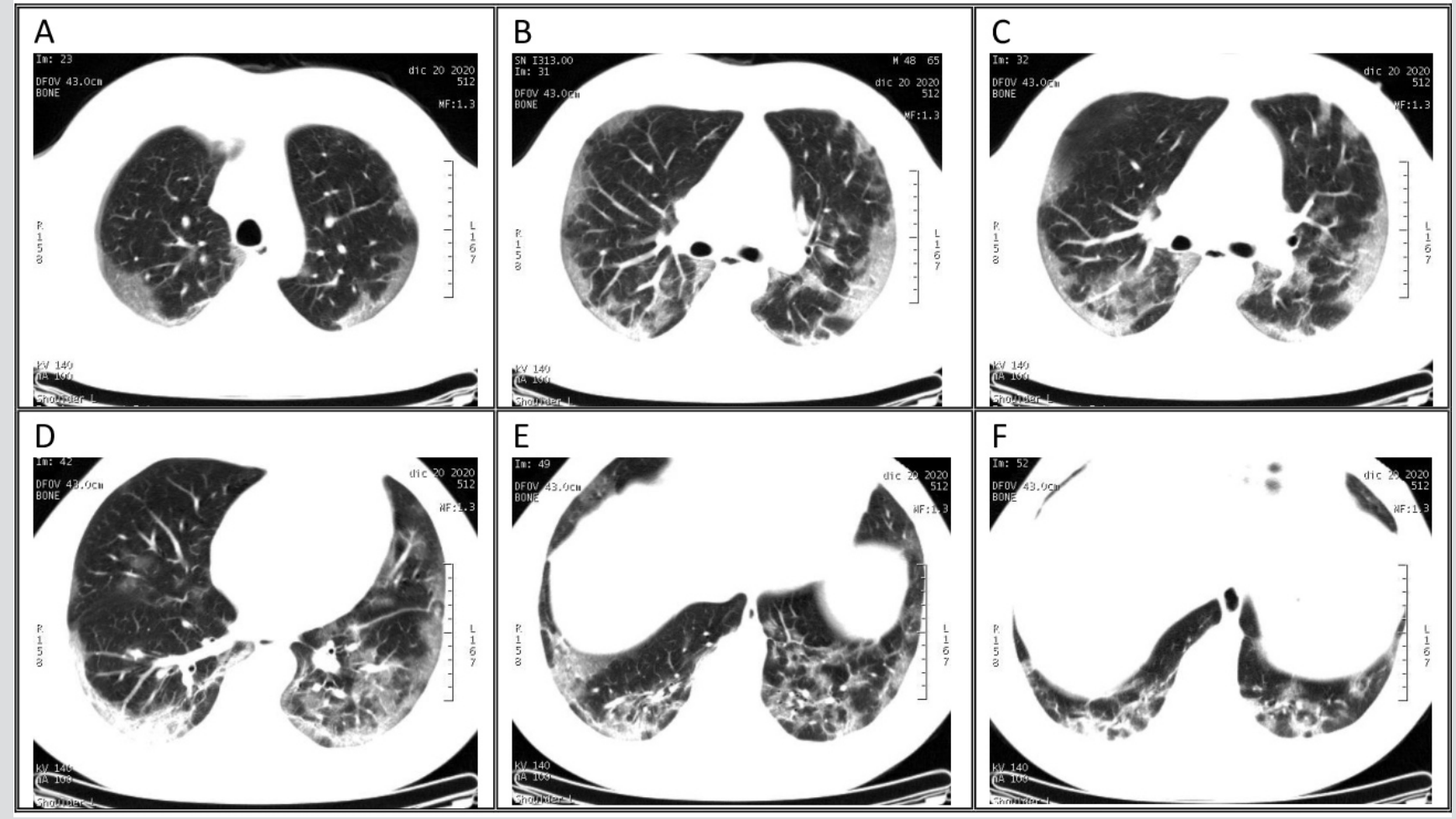

Figure 1. Ground-glass opacity involving both lungs. Respiratory compromise was estimated at $25 \%$ 

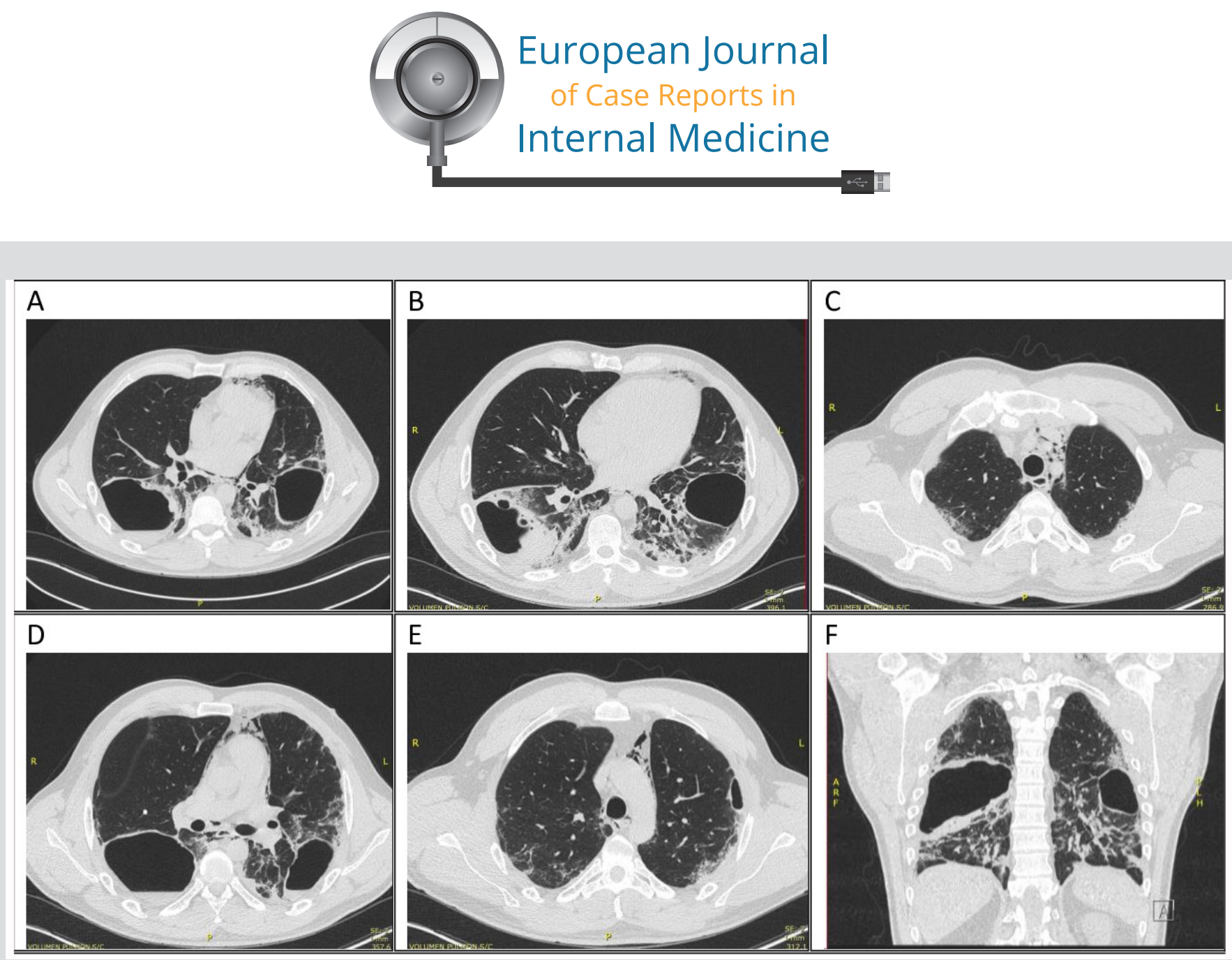

Figure 2. CT scan images. (A) Cavitations in both inferior lobes with air-fluid level in the right inferior lobe and pneumomediastinum. (B) Inflammatory process in the right cavitation. (C) Fibrotic bands with ground-glass opacity in the upper lobes. (D) Calcified nodule in the right lung. (E) Bulla measuring $28 \times 14 \mathrm{~cm}$. (F) CT scan coronal view

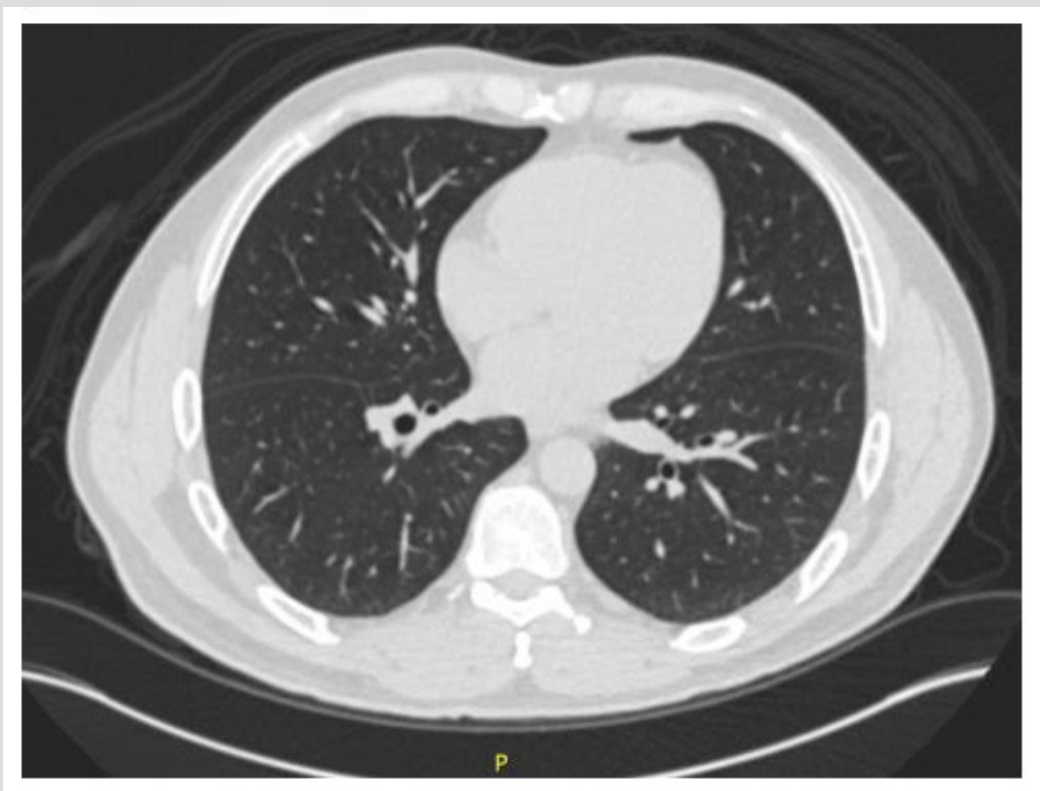

Figure 3. CT scan showing normal lung tissue in the patient 1 year previously

\section{DISCUSSION}

COVID-19 has several presentations and different sequelae and consequences ${ }^{[4]}$.

We have described a patient with no previous history of lung disease, who had a 3-week history of infection with SARS-CoV-2. He recovered well from primary infection but then suddenly presented with haemoptysis, pleuritic pain and malaise. ACT scan showed severe inflammatory 
compromise, with two cavitations, both with signs of active infection and associated with other complications. The patient had an earlier CT scan showing previously healthy lungs.

Our case demonstrates that, although very unusual in COVID-19, patients may develop cavitations and bullae with interstitial lung disease after only 3 weeks of SARS-CoV-2 infection. Sun et al. reported the case of a patient with emphysema, pneumomediastinum and bullae [5]. Zoumot et al. described 12 patients with lung cavitations among 359 patients with COVID-19 pneumonia; all 12 were admitted to the ICU. These findings are considered an under-recognized late complication of severe COVID-19 lung disease ${ }^{[6]}$. Our patient differs from these other cases in many ways: he did not required oxygen supplementation, he did not have respiratory distress or require ICU admission, and the complications presented early in the disease course.

On the other hand, Muheim et al. described two patients who developed lung cavitations several weeks after COVID-19 infection and required high-flow oxygen therapy during hospitalization. These authors proposed the interesting hypothesis of alveolar rupture after episodes of persistent cough that some patients experience during and after diffuse inflammation of the lung parenchyma due to COVID-19 infection ${ }^{[7]}$. This may have been the case with our patient.

To our knowledge, this was one of the first reported cases of bullae or cavitations after SARS-CoV-2 infection in a patient without respiratory distress who did not need ICU admission.

\begin{tabular}{|c|c|c|}
\hline & Result & Normal range \\
\hline \multicolumn{3}{|l|}{ Blood work-up } \\
\hline WBC & 10600 & $4400-113,000$ \\
\hline Haemoglobin & 14.8 & $13.6-17.5$ \\
\hline Platelets & 300,000 & $139,000-403,000$ \\
\hline INR & 1.03 & $0.80-1.20$ \\
\hline Creatinine & 0.93 & $0.50-1.20$ \\
\hline Urea & 22 & $11-50$ \\
\hline DHL & 177 & $135-225$ \\
\hline CRP & 5.14 & $0.00-0.50$ \\
\hline Ferritin & 538.4 & $30-400$ \\
\hline \multicolumn{3}{|l|}{ Blood gas analysis } \\
\hline pH & 7.44 & $7.37-7.45$ \\
\hline pCO2 & 36 & $35-46$ \\
\hline pO2 & 72 & $80-100$ \\
\hline $\mathrm{SpO} 2$ & 95 & $95-100$ \\
\hline HCO3- & 24.5 & $22-28$ \\
\hline \multicolumn{3}{|l|}{ Immunology } \\
\hline Galactomannan & 0.35 & $00.0-0.49$ \\
\hline QuantiFERON - TB Gold & Negative & Negative \\
\hline HIV I and II & Negative & Negative \\
\hline HTLV I and II & Negative & Negative \\
\hline IgM SARS-Cov-2 & Negative & Negative \\
\hline IgG SARS-Cov-2 & Positive & Negative \\
\hline \multicolumn{3}{|l|}{ Cultures } \\
\hline Blood $(\times 3)$ & Negative & Negative after 7 days \\
\hline
\end{tabular}

Table 1. Results of patient investigations

CRP, C-reactive protein; $\mathrm{DHL}$, dehydrogenase lactate; HCO3-, bicarbonate; HIV I and II, human immunodeficiency virus I and II; HTLV I and II, human lymphotropic virus I and II; INR, international normalised ratio; $p \mathrm{O} 2$, partial pressure of oxygen; SpO2, oxygen saturation; SARS-CoV-2, severe acute respiratory syndrome coronavirus 2; WBC, white blood cells. 


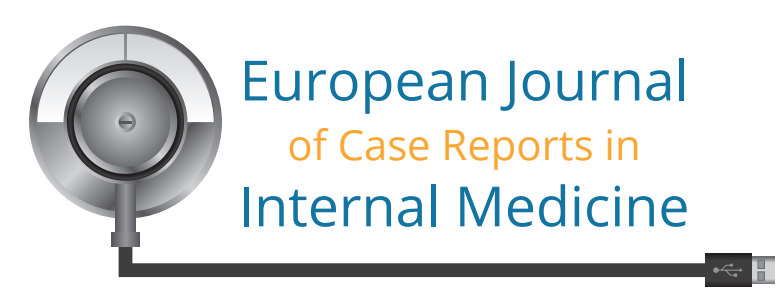

\section{REFERENCES}

1. Azer SA. COVID-19: pathophysiology, diagnosis, complications and investigational therapeutics. New Microbes New Infect 2020;37:100738. https://doi.org/10.1016/ j.nmni.2020.100738

2. Center for Systems Science and Engineering (CSSE) at Johns Hopkins University. Public health: COVID-19 dashboard. Available from: https://systems.jhu.edu

3. George P, Wells A, Jenkins R. Pulmonary fibrosis and COVID-19: the potential role for antifibrotic therapy. Lancet Respir Med 2020;8:807-815. https://doi.org/10.1016/ S2213-2600(20)30225-3

4. Centers for Disease Control and Prevention. Post-COVID conditions: information for healthcare providers. Available from: https://www.cdc.gov/coronavirus/2019-ncov/ hcp/clinical-care/late-sequelae.html

5. Sun R, Liu H, Wang X. Mediastinal emphysema, giant bulla, and pneumothorax developed during the course of COVID-19 pneumonia. Korean J Radiol 2020;21(5):541-544. https://doi.org/10.3348/kjr.2020.0180

6. Zoumot Z, Bonilla MF, Wahla AS, Shafq I, Uzbeck M, EI Lababidi RM, et al. Pulmonary cavitation: an under-recognized late complication of severe COVID-19 lung disease. BMC Pulm Med 2021;21:24

7. Muheim M, Weber FJ, Muggensturm P, Seiler E. An unusual course of disease in two patients with COVID-19: pulmonary cavitation. BMJ Case Rep 2020;13(9):e237967. 